\title{
On the Correlation between Microstructure Homogeneity and Formability in two Multi Phase Steels Treated with Different Cooling Strategies
}

\author{
Marion Bechtold ${ }^{1, a^{*}}$, Marco Witte ${ }^{1, b}$ and Sascha Kluge $e^{2, c}$ \\ ${ }^{1}$ Salzgitter Mannesmann Forschung $\mathrm{GmbH}$, Eisenhüttenstr. 99, 38239 Salzgitter, Germany \\ ${ }^{2}$ formerly ${ }^{1}$, now at Salzgitter Hydroforming $\mathrm{GmbH}$, Gewerbering 26a, 08451 Crimmitschau, \\ Germany \\ am.bechtold@sz.szmf.de, ${ }^{b}$ m.witte@sz.szmf.de, ${ }^{c}$ s.kluge@szhf.de
}

Keywords: Multi phase steel, bainite, tensile test, bending, hole expansion, annealing, EBSD

\begin{abstract}
In the scope of the optimization of multi phase steels, e.g. for the automotive industry, control of the microstructure is essential to tailor the mechanical properties. In this study, two cold rolled steels varying in carbon content were annealed and cooled under different laboratory conditions. The microstructure is investigated using optical and electron microscopy and EBSD. The results are correlated to the mechanical properties obtained from tensile, hole expansion and bending test. It is found that tensile strength and elongation are mainly dependent on martensite volume fraction, while yield strength is less affected by chemical composition or annealing treatment. In contrast, hole expansion capacity and maximum bending angle are significantly improved by the homogenization of the microstructure which is independent of strength and elongation. The microstructure homogeneity is expressed by analyzing the Lorenz curves derived from the kernel average misorientation from EBSD measurements.
\end{abstract}

\section{Introduction}

Cold rolled multi phase steels such as dual phase steels and complex phase steels are the predominant materials in structural and crash-relevant components of many car bodies [1]. In general, high strength levels are desired to reduce sheet thickness and thus vehicle weight, while high formability is needed to realize complex forming operations and high energy absorption in case of crash. However, strength and formability are often found to be negatively correlated and hence, manufacturers have to find a compromise between these two for each application $[2,3]$.

The material's strength is mainly determined by the volume fraction of hard phases, number and size of precipitates as well as grain size. The effect of the microstructure on ductility is more complex. For example, strain hardening capacity is highest in a soft matrix with hard isolated second phase particle which is crucial for forming operations such as drawing and stretching. On the other hand, a uniform microstructure is favorable for good resistance against edge cracking, commonly evaluated by hole expansion test [4,5]. Hence, the microstructure must be specially adjusted for each application. Considering cold rolled and annealed steels, the cooling conditions after annealing play a critical role for the final microstructure. Depending on the type of cooling interrupted or direct quenching, cooling rate and final overageing, the microstructure constituents change in fraction and morphology.

In this study, the influence of the cooling conditions is investigated on a laboratory scale for two alloys varying in carbon content. The microstructures are produced by an annealing simulator and investigated by optical and electron microscopy as well as electron backscatter diffraction (EBSD). The mechanical properties are compared by tensile tests, hole expansion tests and bending tests. 


\section{Experimental Procedures}

The materials used in this study are plain carbon manganese steels with the nominal composition listed in Table 1. They exhibit a typical composition of modern multi phase steels, containing a certain fraction of $\mathrm{Mn}, \mathrm{Si}, \mathrm{Cr}$ and $\mathrm{Mo}$ as well as microalloying elements. The main difference between the steels is the carbon content. The lower carbon content of steel 1 is balanced by a higher fraction of the above mentioned elements. For easy identification, steels will be named LC (low carbon) and $\mathrm{HC}$ (high carbon) steel in the following. The equilibrium phase transformation temperatures (bcc $\rightarrow \mathrm{fcc}$ ) were calculated using ThermoCalc v. 3.1, database TCFE6 and are listed in Table 1 as well.

Table 1: Nominal composition of the materials used in this study, in wt.\% (bal. Fe) and equilibrium phase transformation temperatures $\mathrm{A}_{\mathrm{e} 1}, \mathrm{~A}_{\mathrm{e} 3}$ in ${ }^{\circ} \mathrm{C}$.

\begin{tabular}{|c|c|c|c|c|c|c|}
\hline Steel & $\mathrm{C}$ & $\mathrm{Mn}+\mathrm{Si}$ & $\mathrm{Cr}+\mathrm{Mo}$ & $\mathrm{Nb}+\mathrm{Ti}+\mathrm{V}+\mathrm{B}$ & $\mathrm{A}_{\mathrm{e} 1}$ & $\mathrm{~A}_{\mathrm{e} 3}$ \\
\hline 1: $\mathrm{LC}$ & 0.10 & 2.3 & 0.6 & 0.05 & 694 & 846 \\
\hline 2: $\mathrm{HC}$ & 0.15 & 2.1 & 0.3 & 0.02 & 678 & 807 \\
\hline
\end{tabular}

The cold-rolled $2 \mathrm{~mm}$ thick materials were cut into sheets of $210 \times 450 \mathrm{~mm}^{2}$ (TD x RD) and subjected to annealing in a Vatron annealing simulator. The annealing schedule is schematically drawn in Fig. 1. Heating rate, soaking temperature and time were constant. In the intermediate quench (IQ) route, cooling was interrupted at $450{ }^{\circ} \mathrm{C}$ which is the zinc bath temperature applied in hot dip galvanizing, while in the direct quench (DQ) route, continuous cooling to room temperature was applied.

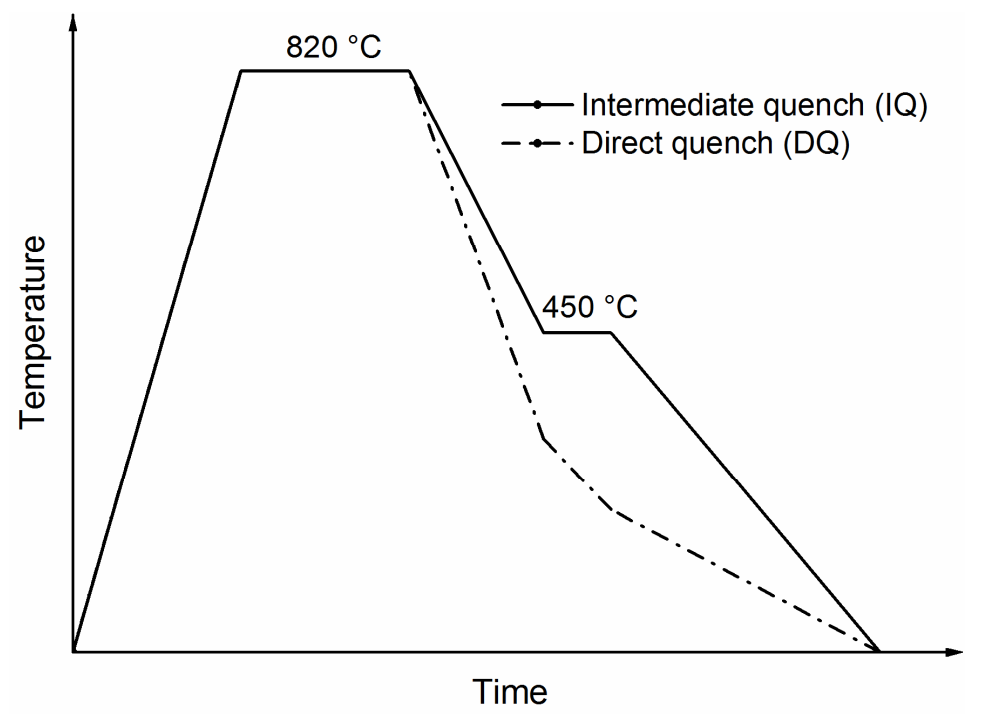

Fig. 1: Schematic drawing of the annealing cycles applied in this study.

Sample preparation for light optical microscopy (LOM), scanning electron microscopy (SEM) and electron backscatter diffraction (EBSD) was performed with standard grinding and polishing procedures finishing with OPS polishing for several minutes. For LOM and SEM, the samples were subjected to slight Nital etching. EBSD measurements were performed on a Zeiss Supra 55VP SEM equipped with a high-speed DigiView $5 \mathrm{CCD}$ camera, using a voltage of $15 \mathrm{kV}$ at a working distance of $16 \mathrm{~mm}$. The size of the measured areas was $150 \times 150 \mu \mathrm{m}^{2}$ and the step size $0.1 \mu \mathrm{m}$.

Tensile tests were performed according to DIN EN ISO 6892-1 on two longitudinal specimens for each material and annealing treatment. Hole expansion ratio (HER) was determined according to ISO 16630 as average of six measurements, discarding the minimum and maximum value. To determine the maximum bending angle, 3-point plate bending tests according to VDA 238-100 were 
performed. Three samples were tested parallel and perpendicular to the rolling direction, respectively.

\section{Results and Discussion}

Microstructure. To gain an overview of the phase constituents and morphological characteristics of the materials, micrographs were taken at a 1000:1 magnification (Fig. 2). All steels consist of a ferritic matrix with martensite islands being mainly smaller than the ferrite grains. The HC-IQ (high carbon steel, intermediate quench) is the only specimen that contains a significant amount of bainite and tempered martensite. It is obvious that microstructure banding is much more pronounced in the high carbon steels (right column). Comparing the direct quenched samples (a and b), it turns out that both the ferrite and the martensite island size is reduced in the LC steel, probably due to the higher microalloying content. A closer look in the SEM reveals that the ferrite in LC-DQ is more often dislocated or divided into subgrains than in HC-DQ. The EBSD data confirm this finding by a doubled fraction of low-angle grain boundaries (LAGB) (Table 2). The martensite island size is further reduced in the LC steel by intermediate quenching treatment (c). Here, a small fraction of bainite (granular type) forms and the martensite volume fraction is reduced in comparison to direct quenching. In the HC steels, the IQ treatment does not lead to finer grain size but to the formation of lath-like bainite (mainly lower bainite) and to tempering of martensite.
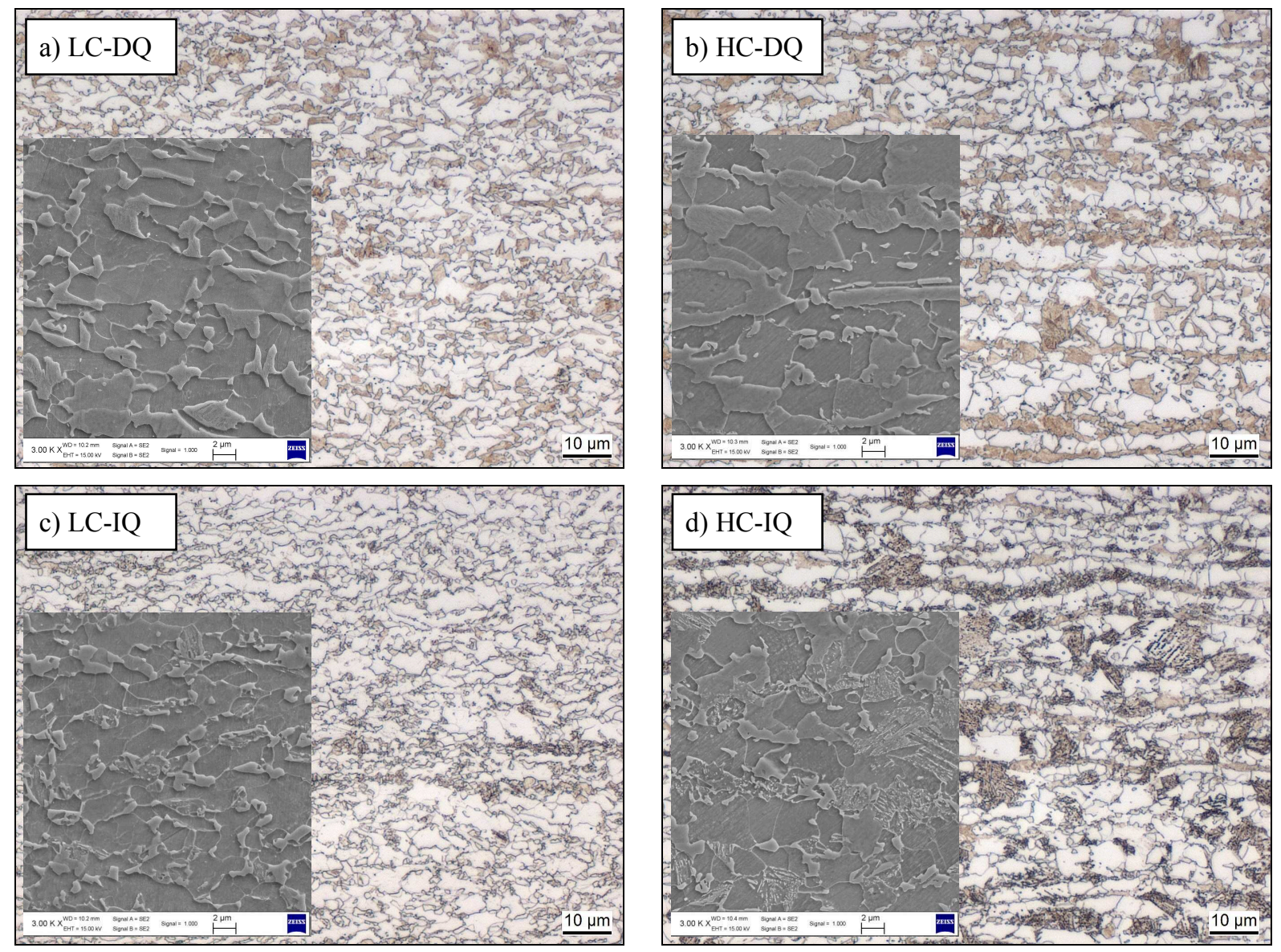

Fig. 2: Light optical and scanning electron micrographs of the investigated high carbon (HC) and low carbon (LC) steel observed after direct (DQ) and intermediate quenching (IQ).

Deeper insight is obtained by analyzing EBSD data. Fig. 3 shows the kernel average misorientation (KAM) maps. The KAM is here calculated as the average misorientation angle between a point and its second neighbors, discarding all misorientations above $4^{\circ}$. The KAM is a measure for local orientation gradients [6], geometrically necessary dislocations as well as 
subgrains. It is obvious that the HC samples show much higher KAM contrast between the soft ferritic and the hard martensitic/bainitc phase than the LC samples. Thus, we assume that the hardness difference between the phases is lower for the LC steel, although this assumption needs to be approved e.g. by nanoindentation measurements. Comparing the quenching cycles for each steel, it turns out that intermediate quenching leads to slight homogenization of the microstructure in terms of local distortions.
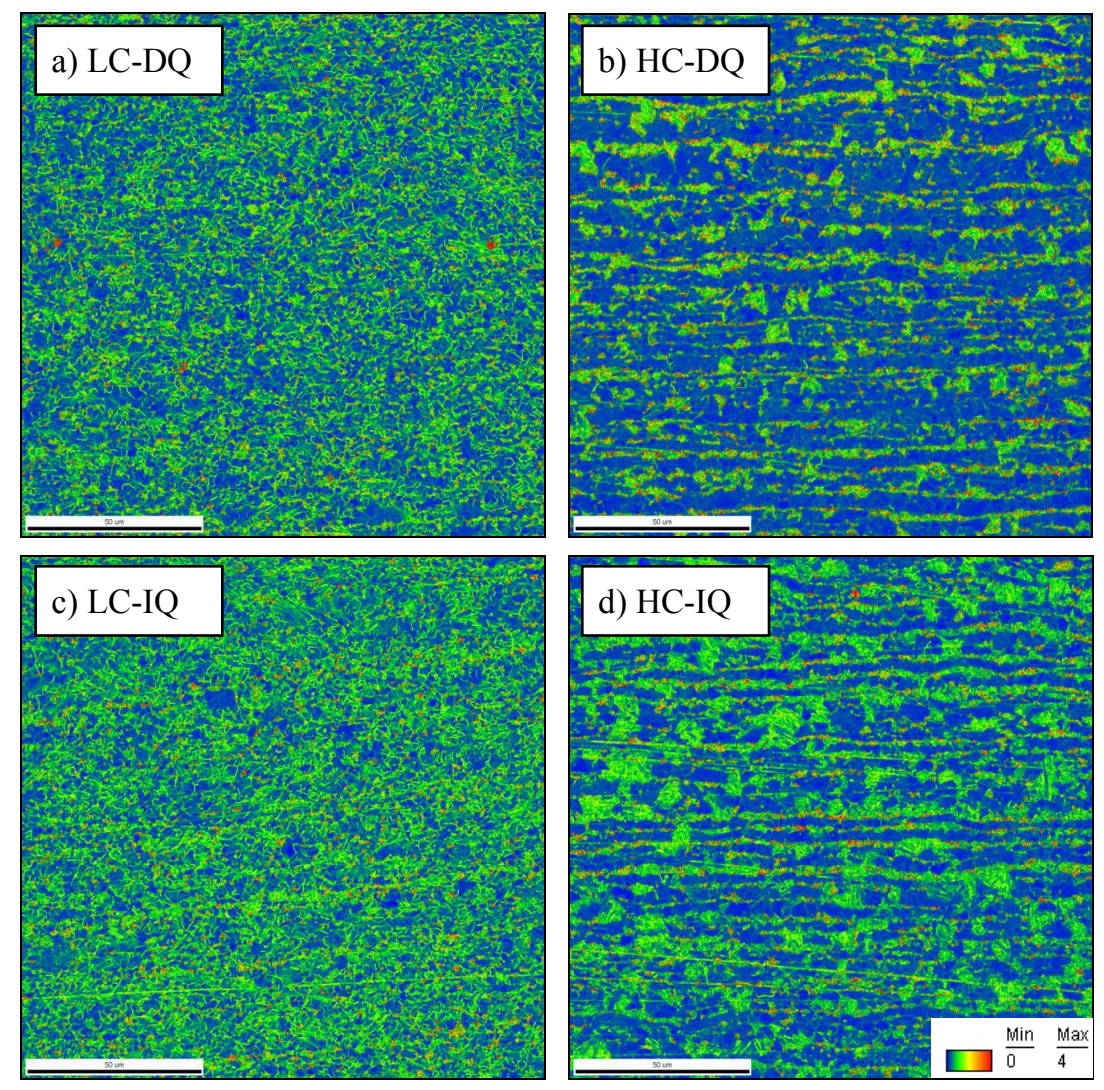

Fig. 3: Kernel average misorientation $(\mathrm{KAM})$ maps $\left(2^{\text {nd }}\right.$ neighbor, maximum angle $\left.4^{\circ}\right)$ of the investigated high carbon (HC) and low carbon (LC) steel observed after direct (DQ) and intermediate quenching (IQ).

To obtain more quantitative information from the KAM value, a statistical analysis was performed according to the method described in Ref. [7]. This method is applied in this study as a pixel-based routine and yields the homogeneity $\mathrm{H}$ as a measure for the contrast between soft, dislocation-free and hard dislocated phases. $H$ is calculated from the area $A_{L}$ under the Lorenz curves in Fig. $4\left(\mathrm{H}=2 \mathrm{~A}_{\mathrm{L}}\right)$. 


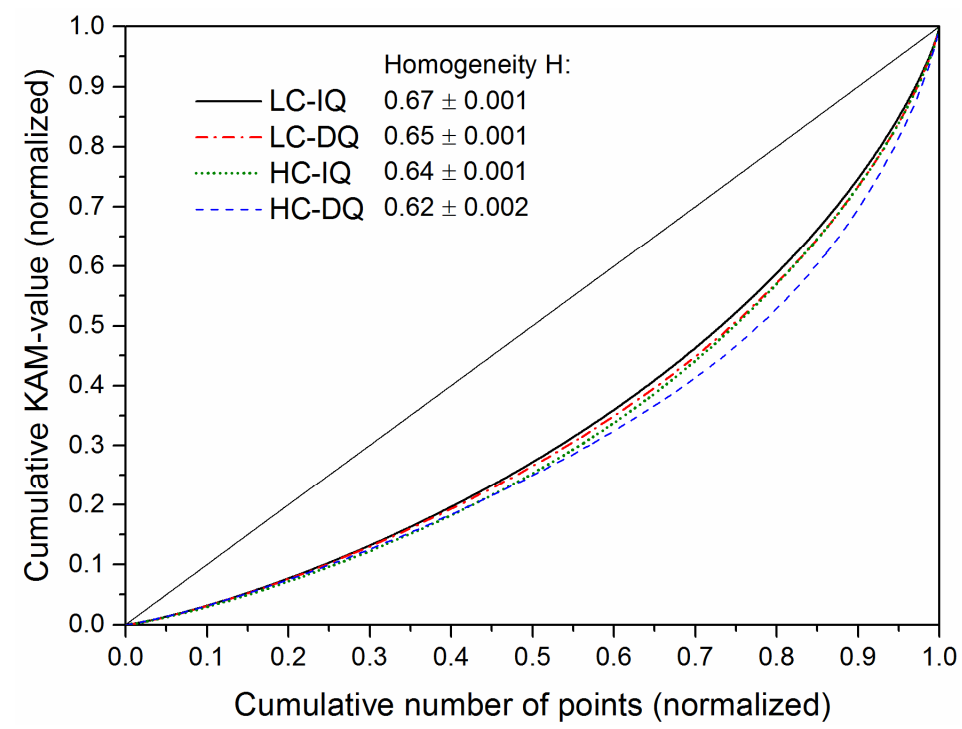

Fig. 4: Lorenz curves for the calculation of the homogeneity $\mathrm{H}$ from the kernel average misorientation angles $\left(2^{\text {nd }}\right.$ neighbor, maximum angle $\left.4^{\circ}\right)$ of the investigated low carbon (LC) and high carbon (HC) steel after direct quenching (DQ) and intermediate quenching (IQ). For comparison also the curve for ideal homogeneity $\mathrm{H}=1$ is shown.

A totally uniform distribution would lead to a value of $\mathrm{H}=1$. From Fig. 4, it is seen that the lowest homogeneity is present in the HC-DQ sample, while sample LC-IQ shows the highest homogeneity which is in perfect accordance with Fig. 3. Due to the good statistics of the measurement ( $>2$ million measurement points in each EBSD scan), the calculated error as indicated in Fig. 4 is very low. Table 2 summarizes the most relevant findings of the microstructure analysis.

Table 2: Metallographic data of the investigated steels (H: homogeneity, LAGB: low-angle grain boundaries $2-15^{\circ}$, HAGB: high-angle grain boundaries $>15^{\circ}$ ).

\begin{tabular}{|c|c|c|c|c|c|c|c|c|}
\hline Steel & Quench & $\%$ Ferrite & \%Bainite & \%Martensite & $\begin{array}{c}\text { \%Retained } \\
\text { austenite }\end{array}$ & H [-] & \%LAGB & \%HAGB \\
\hline \multirow{2}{*}{ LC } & DQ & $\begin{array}{c}60, \text { partly } \\
\text { dislocated }\end{array}$ & 0 & 40 & 0.1 & 0.65 & 12 & 88 \\
\cline { 2 - 9 } & IQ & $\begin{array}{c}80, \text { partly } \\
\text { dislocated }\end{array}$ & $\begin{array}{c}5, \\
\text { granular }\end{array}$ & 15 & 1.0 & 0.67 & 13 & 87 \\
\hline \multirow{2}{*}{ HC } & DQ & 60 & 0 & 40 & 0.2 & 0.62 & 6 & 94 \\
\cline { 2 - 9 } & IQ & 65 & $\begin{array}{c}25, \\
\text { lath-like }\end{array}$ & $\begin{array}{c}10, \text { partly } \\
\text { tempered }\end{array}$ & 1.1 & 0.64 & 7 & 93 \\
\hline
\end{tabular}

Tensile test. The average values of two longitudinal tensile tests are shown in Fig. 5. While the yield strength (YS) is comparable for all steels, the tensile strength (TS) is significantly lowered $(\sim 100 \mathrm{MPa})$ when cooling is interrupted at $450{ }^{\circ} \mathrm{C}$ which can be easily explained by the reduced martensite fraction (Table 2). At the same time, total elongation (TE) is increased by around $5 \%$, and the n-value is higher as well. For a given cooling treatment, the chemical composition has a minor influence on mechanical properties. 


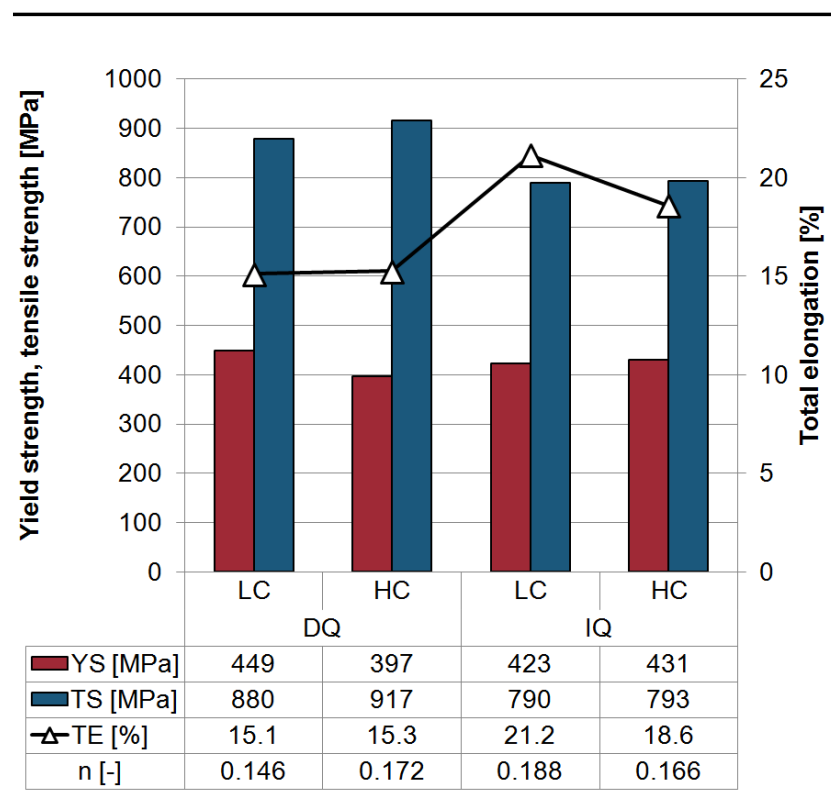

Fig. 5: Results of the tensile test.

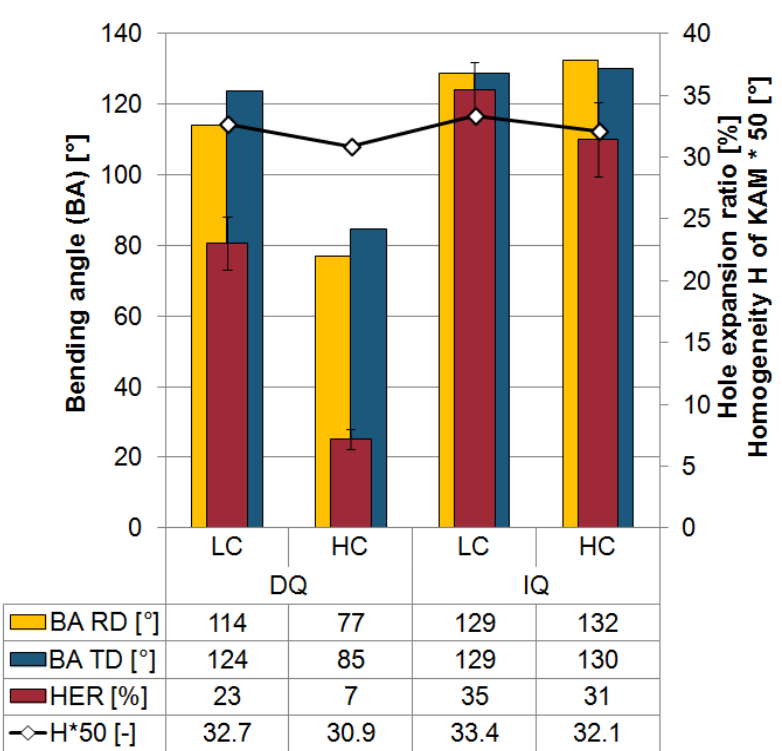

Fig. 6: Results of the 3-point plate bending test and the hole expansion test, correlated with homogeneity $\mathrm{H}$.

Hole Expansion and Bending Test. The influence of chemical composition and cooling cycle on maximum bending angle and hole expansion ratio (HER) is shown in Fig. 6. For the direct quenched materials, the HC steel exhibits significantly lower bending angles and HER, while this effect of chemical composition is much less pronounced in case of the intermediate quenched steels. Comparing identical compositions, we observe improved formability properties for the IQ treatment, the tendency being most evident for the HC steel. There is no consistent influence of test direction on maximum bending angle, i.e. no pronounced anisotropy.

When correlating the mechanical properties with the microstructure, we observe that hole expansion and bending angle are strongly dependent on phase constituents and homogeneity of the microstructure. When a certain fraction of bainite and/or dislocated ferrite is present (LC samples, IQ treatment), HER and bending angle increase. Reduced microstructure banding leads to further improvement of formability. The retained austenite fraction, determined by EBSD, is very low in these steels and is thus not considered to contribute to micromechanical behavior. The homogeneity of the microstructure in terms of the presumed microhardness differences is best represented by the homogeneity $\mathrm{H}$ derived from KAM. In Fig. 6, the homogeneity is additionally plotted. We see that there is a good correlation between high homogeneity (high $\mathrm{H}$ value) and high formability. This correlation fails when comparing LC-DQ and HC-IQ, the former having higher $\mathrm{H}$ value but lower formability. Here, the influence of tempered martensite in HC-IQ seems to dominate the effect of a homogeneous microstructure. Interestingly, the formability of all samples is less dependent on tensile strength and total elongation (compare tendencies in Fig. 5 and Fig. 6). It is important to note that the polygonal ferrite fraction, which is generally associated with high formability, is not the decisive parameter to obtain good hole expansion and bending angle in this study. Instead, a homogeneous microstructure with a rather dislocated ferrite, bainite and tempered martensite is highly beneficial for the investigated types of forming operations.

\section{Summary}

Two steels with different carbon content $(0.15 \mathrm{wt} . \% \mathrm{C}, \mathrm{HC}$, and $0.10 \% \mathrm{C}, \mathrm{LC})$ were treated with two cooling conditions (direct quenching, DQ, and intermediate quenching, IQ). The microstructures and mechanical properties were determined and compared. The main conclusions are: 
- In both steels, a ferritic-martensitic microstructure is produced. Dislocated ferrite, granular bainite or tempered martensite are formed in the LC steels and the HC steel after IQ treatment.

- The yield strength is nearly equal for all steels, while tensile strength is higher after the DQ treatment due to a higher martensite fraction.

- There is a strong correlation of formability (hole expansion ratio and maximum bending angle) and microstructure homogeneity (quantified by the parameter from the Lorenz curves of the KAM distributions), which is independent of the tensile strength and total elongation, but can be ruled out by the presence of bainite and/or tempered martensite.

- Improvement of microstructure homogeneity and thus of formability are achieved in the LC steels and by IQ treatment.

- When designing multi-phase steels by accurate microstructure control considering both chemical analysis and cooling treatments, it is possible to improve the formability without sacrificing strength.

\section{References}

[1] FutureSteelVehicle, EDAG, Engineering Report, www.worldautosteel.org., 2011.

[2] D. Bhattacharya, in: Y. Weng, Y. Gan, H. Dong (Eds.), Advanced Steels, Springer, Berlin, 2011, pp. 163-176.

[3] D. K. Matlock, J. G. Speer, E. De Moor und P. J. Gibbs, JESTECH 15 (2012) 1-12.

[4] S. Chatterjee and H. Bhadeshia, Mater. Sci. Tech. 23 (2007) 606-609.

[5] D. Gutiérrez, J. Escaler, A. Lara, D. Casellas and J. Pra, in IDDRG, Bilbao, Spain, 2011.

[6] M. Calcagnotto, D. Ponge, E. Demir und D. Raabe, Mater. Sci. Eng. A 527 (2010) 2738-2746.

[7] P. Rossi, M. Engstler und F. Mücklich, Practical Metallography 51 (2014) 180-199. 